\title{
Improvement of watershed flood forecasting by typhoon rainfall climate model with an ANN-based southwest monsoon rainfall enhancement
}

\author{
Tsung-Yi Pan ${ }^{\mathrm{a}}$, Yi-Ting Yang ${ }^{\mathrm{b}, *}$, Hung-Chi Kuo ${ }^{\mathrm{b}}$, Yih-Chi Tan ${ }^{\mathrm{a}, \mathrm{c}}$, Jihn-Sung Lai ${ }^{\mathrm{a}, \mathrm{d}}$, Tsang-Jung Chang ${ }^{\mathrm{a}, \mathrm{c}}$, \\ Cheng-Shang Lee ${ }^{\text {b,e }}$, Kathryn Hua Hsu ${ }^{a}$ \\ ${ }^{a}$ Center for Weather Climate and Disaster Research, National Taiwan University, Taipei, Taiwan, ROC \\ ${ }^{\mathrm{b}}$ Department of Atmospheric Sciences, National Taiwan University, Taipei, Taiwan, ROC \\ ${ }^{c}$ Department of Bioenvironmental Systems Engineering, National Taiwan University, Taipei, Taiwan, ROC \\ ${ }^{\mathrm{d}}$ Hydrotech Research Institute, National Taiwan University, Taipei, Taiwan, ROC \\ ${ }^{\mathrm{e}}$ Taiwan Typhoon and Flood Research Institute, Taipei, Taiwan, ROC
}

\section{A R T I C L E I N F O}

\section{Article history:}

Available online xxxx

\section{Keywords:}

Southwest monsoon

Statistical typhoon rainfall forecasting

Artificial neural network

Water vapor flux

Flood forecasting

\begin{abstract}
S U M M A R Y
This paper improves the typhoon flood forecasting over a watershed in a mountainous island of Taiwan. In the presence of the stiff topography in Taiwan, the typhoon rainfall is often phased-locked with terrain and the typhoon rainfall in general is best predicted by the typhoon rainfall climate model (TRCM) (Lee et al., 2006). However, the TRCM often underestimates the rainfall amount in cases of slowing moving storms with strong southwest monsoon supply of water vapor flux. We apply an artificial neural network (ANN) based southwest monsoon rainfall enhancement (AME) to improve TRCM rainfall forecasting for the Tsengwen Reservoir watershed in the southwestern Taiwan where maximum typhoon rainfall frequently occurred. Six typhoon cases with significant southwest monsoon water vapor flux are used for the test cases. The precipitations of seven rain gauge stations in the watershed and the southwest monsoon water vapor flux are analyzed to get the spatial distribution of the effective water vapor flux threshold, and the threshold is further used to build the AME model. The results indicate that the flux threshold is related to the topographic lifting of the moist air, with lower threshold in the upstream high altitude stations in the watershed. The lower flux threshold allows a larger rainfall amount with AME. We also incorporated the rainfall prediction with a state space neural network (SSNN) to simulate rainfall-runoff processes. Our improved method is robust and produces better flood predictions of total rainfall and multiple rainfall peaks. The runoff processes in the watershed are improved in terms of coefficient of efficiency, peak discharge, and total volume.
\end{abstract}

(c) 2013 Elsevier B.V. All rights reserved.

\section{Introduction}

There are three to five typhoons each year influencing Taiwan with torrential rainfall. Flood forecasting is one of the critical issues of reservoir operations, especially for those reservoirs built in watershed with stiff topography. The stream in the mountainous watershed is rapid and the time of concentration is approximately 3-5 h. The very short concentrated time pose serious challenges for flood forecasting and reservoir operation during typhoon landfall periods. The Taiwan typhoon rainfall is often phased-locked with the Central Mountain Range, with maximum rainfall often occurring on the windward side of the topography. Thus knowing the position of typhoon allows the forecasting of a precipitation pattern and the amount of rainfall from the typhoon climatology history. The quantitative typhoon rainfall prediction in Taiwan is

\footnotetext{
* Corresponding author. Tel.: +886 23366 3945; fax: +886 223671291.

E-mail address: d97229001@ntu.edu.tw (Y.-T. Yang).
}

often used with a statistical approach based on the relation between the observed rainfall pattern and the tracks of typhoon in the climatology model (e.g., Lee et al., 2006; the Typhoon Rainfall Climate Model, TRCM). The TRCM used 371 stations over Taiwan during 1989-2001. The model often gives reasonable precipitation estimates on each rain gauge station for $24-36 \mathrm{~h}$ time scale by a given typical cyclone center.

Typhoon Morakot 2009, with significant southwest monsoon flow, produced a record-breaking rainfall of $2361 \mathrm{~mm}$ in time spans of $48 \mathrm{~h}$ in the upstream of the Tsengwen Reservoir watershed (Alishan station). The extreme rainfall event is caused by the very slow moving of Typhoon Morakot and also the significant southwest monsoon water vapor supply (Chien and Kuo, 2011). The importance of the monsoon flow water vapor supply for the typhoon heavy rainfall is recognized in many of the recent studies (Chien et al., 2008; Lee et al., 2008; Ge et al., 2010; Hong et al., 2010). Because TRCM is based on the typhoon climatology of all scenarios, it may underestimate the typhoon rainfall in the presence of strong 
southwest monsoon flow. The southwest monsoon flow is a large scale meteorological feature that is well observed, thus it is possible to improve the typhoon flood forecasting with monsoon flow water vapor enhancement over a watershed.

The artificial neural network (ANN) algorithm is useful in rainfall forecasting, as the algorithm is flexible and data-driven learning in building model without prior assumptions concerning the data distribution and also takes into account the nature of nonlinearity (Gardner and Dorling, 1998). In order to achieve an accurate rainfall forecasting, many meteorological factors are selected as the inputs, including past observed rainfall, typhoon's characteristics, and satellite data (French et al., 1992; Olsson et al., 2004; Lin and Chen, 2005; Lin et al., 2009; Hsu et al., 1997; Bellerby et al., 2000; Hong et al., 2004; Chen et al., 2008).

The ANN approach is also useful in the rainfall-runoff processes (Whitley and Hromadka, 1999; Anctil et al., 2005; Chang and Chen, 2003; Cigizoglu, 2005; Hu et al., 2005; Imrie et al., 2000; Wang et al., 2009; Deka and Chandramouli, 2005; Lange, 1999; El-Shafie and El-Manadely, 2011). In these studies, the feedforward neural network (FNN) is adopted to perform rainfall-runoff processes. There may be some limitations of model calibration and simulation for a dynamical system, including using an inefficient process of trial and error to determine the optimum structure with appropriate number and configuration of its neurons in hidden layers (Imrie et al., 2000) and no dynamics involved due to the static structure of FNN (Chiang et al., 2004). This deficiency in flood forecasting may be remedied by a state space neural network (SSNN) with dynamics (Pan and Wang, 2004). Furthermore, Pan et al. (2007) demonstrated that DLRNN (one type of SSNNs) only needs the current rainfall as the input to get a satisfactory hydrograph while an FNN, which has the same input and number of weights as the DLRNN, performs rainfall-runoff processes poorly.

Pan et al. (2011) used an ANN-based southwest monsoon rainfall enhancement (AME) to improve TRCM rainfall forecasting for two mountain stations Alishan and Yushan with cumulative rainfall over $400 \mathrm{~mm}$. Their result suggested that AME improves TRCM rainfall predictions significantly in both mountain stations. In this paper, we update the database of TRCM to include recent typhoons with strong southwest monsoons. We extend the previous work to investigate the impacts of the southwest monsoon on typhoon rainfalls in the Tsengwen Reservoir watershed by TRCM with AME. The rainfall-runoff processes are simulated with the SSNN from the improved TRCM rainfall predictions. Based on the SSNN, a short term rainfall-runoff forecasting for direct runoff of time $t+1 \sim t+3$ could be performed from the observed rainfall and an experiential phi index of time $t$ for operational flood forecasting work (Pan and Wang, 2004). Therefore, the forecasting is performed in this study because the hydrological responses of time $t+1 \sim t+3$ are carried out based on the observed rainfall of time $t$ and more rainfall predictions of time $t+1 \sim t+3$ via TRCM with AME. Consequently, we evaluate the performance of hydrological models for $1-3 \mathrm{~h}$ ahead flood forecasting. The descriptions of methods and data are in Section 2. The results and conclusions are in Sections 3 and 4, respectively.

\section{Methods and data}

\subsection{Study area and European Centre for Medium-Range Weather Forecasts-Tropical Ocean Global Atmosphere (CMWF-TOGA) data}

We select the Tsengwen Reservoir watershed as our study area. Located in southern Taiwan, the Tsengwen Reservoir watershed is on the upstream of the Tsengwen creek with an area of $481 \mathrm{~km}^{2}$, a mean annual precipitation of $2700 \mathrm{~mm}$ approximately, and a mean annual stream flow of $29.0 \mathrm{~m}^{3} \mathrm{~s}^{-1}$. The elevation of the watershed ranges from $232.5 \mathrm{~m}$ to $2609.0 \mathrm{~m}$ and average slope is $54.4 \%$. The Tsengwen Reservoir is located in the downstream of the watershed elevated at $133 \mathrm{~m}$ altitude. The topography, location of hydrological and rain gauge stations in the Tsengwen Reservoir watershed is shown in Fig. 1(a). The geographic orientation of the Tsengwen Reservoir watershed implies favorable condition for heavy precipitation, especially in the west half (windward side in general) of the watershed, where most of the rain gauge stations and the hydrological station are located. The stations are in the northeasternsouthwestern orientation with the highest station Alishan $(2413 \mathrm{~m})$ and the lowest station Tsengwen (207 m).

To quantify the southwest monsoon water vapor flux (SWFlux), we use six hourly (at 0000, 0600, 1200 and 1800 Coordinated Universal Time (UTC)) advanced gridded operational analyses from European Centre for Medium-Range Weather Forecasts-Tropical Ocean Global Atmosphere (ECMWF-TOGA) with $1.125^{\circ} \times 1.125^{\circ}$ resolution on $925 \mathrm{~h} \mathrm{~Pa}$. We compute the SWFlux at each grid with the total wind and the specific humidity. Fig. 2 shows the differences of $925 \mathrm{~h} \mathrm{~Pa}$ wind speed and SWFlux between the six typhoons during the post-landfall period and the averaged pattern calculated from June to August during 2004 to 2009. Fig. 2 illustrates significant SWFlux for these typhoon cases, and the SWFlux provides the needed water vapor for post-landfall extreme rainfall. Although the SWFlux of Typhoon Kalmaegi is the weakest, but it is still stronger than climatology. The green rectangular region $\left(16.875-22.5^{\circ} \mathrm{N}, 110.25-120.375^{\circ} \mathrm{E}\right.$ with totally 60 grids near Taiwan) in Fig. 2 is used for detecting the SWFlux (Pan et al., 2011). The averaged SWFlux in the green region is computed as equation

$\overline{F l u x}=\frac{\sum_{i=1}^{60}\left(u_{i}^{2}+v_{i}^{2}\right)^{1 / 2} \times q_{i}}{60}$

where $q_{i}$ is the specific humidity of the $i$ th grid, and $u_{i}$ and $v_{i}$ are zonal and meridional velocity $\left(\mathrm{m} \mathrm{s}^{-1}\right)$ of the $i$ th grid, respectively. With southwesterly flow in mind, the $\overline{F l u x}$ is calculated only when $u>0$ and $v>0$. Because the water vapor flux is estimated from ECMWF wind field and humidity field, the major possible errors are come from temporal and spatial resolution and the lack of the observed data over ocean. The temporal and spatial resolutions are $6 \mathrm{~h}$ and $1.125^{\circ}$, respectively. On the other hand, the data sets are based on quantities analysis or computed within the ECMWF data assimilation scheme. This method has reduced the error of few observed ocean data because satellite data has included.

\subsection{Typhoon rainfall climate model (TRCM) and typhoon cases}

Lee et al. (2006) developed the TRCM, which used 371 stations during 1989-2001. The domain of TRCM is confined from $19^{\circ} \mathrm{N}$ to $27^{\circ} \mathrm{N}$ and from $118^{\circ} \mathrm{E}$ to $126^{\circ} \mathrm{E}$, which is divided by 256 sub grids $\left(0.5^{\circ} \times 0.5^{\circ}\right)$. The TRCM model comprises of a set of rainfall climatology maps, which is for each rainfall station. When the typhoon center is located at any grid box, the climatology hourly rainfall values for 371 stations could be estimated from the maps. Thus, knowing the typhoon tracks can estimate an hourly precipitation pattern and amount from climatology history. The coefficient of determinations $\left(R^{2}\right)$ between model estimated and observed cumulative rainfall are 0.7 and 0.81 for Dan-Shui (DSH) River and Kao-Ping (KPS) River basins, respectively. Moreover, The $R^{2}$ are 0.69 and 0.73 if the hourly rainfall individual stations in DSH and KPS were considered. This model often gives reasonable typhoon precipitation estimates on 371 rain gauge stations cumulus rainfall and rainfall intensity $\left(\mathrm{mm} \mathrm{h}^{-1}\right)$ for $24-36 \mathrm{~h}$. In particular, the performance is very well in KPS basins (Lee et al., 2006) near the Tsengwen Reservoir watershed at southwest Taiwan.

To make TRCM more reliable to our study, we update the TRCM database from 1989 to 2008 . However, we find that the predicted 
(a) The watershed of Tsengwen reservoir

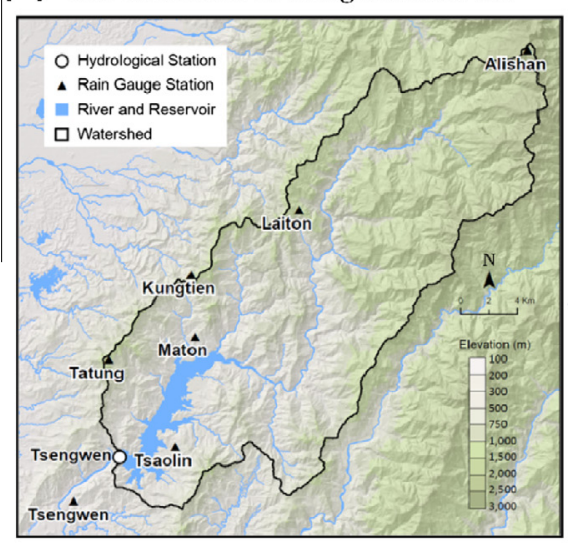

(b) Typhoon track

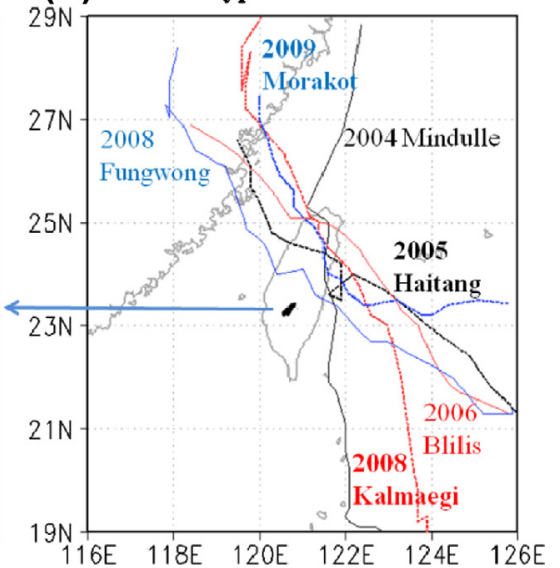

Fig. 1. (a) The topography, location of hydrological and rain gauge stations in the Tsengwen Reservoir watershed; (b) The tracks of six selected typhoon events.

rainfall still much smaller than the observations in the Tsengwen Reservoir watershed. Thus, we choose six typhoon cases with strong southwest monsoon for our AME purpose. Our work is to compare the TRCM results with the TRCM with AME results over the Tsengwen Reservoir watershed. The importance of the southwest monsoon water vapor supply for the heavy rain event is emphasized in Chien and Kuo (2011), among many others. There are six most recent typhoons Mindulle (2004), Haitang (2005), Bilis (2006), Kalmaegi (2008), Fungwong (2008), and Morakot (2009) that are with strong southwest monsoon flow. We used these six typhoons for our cases of AME. The typhoon tracks are shown in the right panel of Fig. 1(b). With southwest monsoon flow persistent, the typhoons produce heavy rainfall not just in the landfall period but also the post-landfall period. The precipitation of post-landfall defined as the precipitation during the time from the typhoon departure point of Taiwan to $100 \mathrm{~km}$ offshore. The profiles of six typhoon events with total rainfall amount in the Tsengwen Reservoir watershed are summarized in Table 1. Table 1 indicates that, with exception of the Typhoon Kalmaegi, most of the Tsengwen Reservoir watershed rainfall occurred in the postlandfall period. In addition, Table 2 suggests that Typhoon Bilis (Typhoon Kalmaegi) is with the fastest translation speed in the landfall period (post-landfall period), among all six selected cases.

\subsection{An ANN-based monsoon rainfall enhancement of TRCM}

We use the $\overline{\text { Flux }}$ to improve the TRCM rainfall prediction in each station, and calculate the difference between TRCM rainfall amount and observation as a function of time in each rain gauge station (DIFF). In order to identify a threshold of $\overline{F l u x}$ for each rain gauge, each 30 data of $\overline{F l u x}$ are averaged with increasing rainfall intensity, and a transition point is carried out based on the maximum slop difference of two linear regressions for two segments in a scatter plot of the DIFF data ( $x$-axis) and $\overline{\text { Flux }}(y$-axis) in each rain gauge station (Brunder et al., 1981; Pan et al., 2011). Therefore, the determination of the transition point for the data of averaged Flux vs increasing rainfall intensity can be represented by a set of intersecting regression lines (Brunder et al., 1981). The maximum difference of the slops of two regression lines based on two data set segmented by the DIFF of a transition point means a sharp change in slope of a scatter of the Flux and DIFF data. Then, the significant contribution of Flux to the DIFF could be determined for the Flux over the threshold of effective moisture flux that is the intercept of the regression line based on the data set with DIFF greater than the DIFF of the transition point. All $\overline{F l u x}$ over the threshold is regarded as the EFlux which is used to enhance the typhoon rainfall. An FNN is then applied to estimate the residual from linear model to the DIFF. The AME thus is composed by the relation between the EFlux and the evaluated extra rainfall. Our approach is similar to Pan et al. (2011) except that we neglect the wind field and use the residual rainfalls of time $t-1 \mathrm{~h}$, $t-2 \mathrm{~h}$ and $t-3 \mathrm{~h}$ as inputs. The neglect of wind filed input is to avoid the information redundancy of water vapor flux and wind field. Briefly, the output of the FNN is the residual rainfall of time $t$ based on the inputs including the SWFlux of time $t$, and residual rainfalls of time $t-1 \mathrm{~h}, t-2 \mathrm{~h}$ and $t-3 \mathrm{~h}$.

\subsection{State space neural network for hydrological modelling}

Flood forecasting is a difficult task in simulation of the whole hydrological cycle especially when the time of concentration is short in Taiwan's watershed with topography. Pan and Wang (2004) introduced a dynamic recurrent neural network with state space form, SSNN, to improve the flood prediction. Based on the state space theory, the transition of a hydrological system could be represented as unit hydrographs for investigating the rainfallrunoff processes (Pan et al., 2007). Our methods are based on Pan and Wang (2004) and Pan et al. (2007) and are summarized below. The mathematical form of a SSNN can be written as

$\hat{x}_{i+1}=W^{h} \cdot f_{1}\left(W^{r} \cdot x_{t}+W^{i} \cdot u_{t}+B^{h}\right)$

$\hat{y}_{t}=W^{o} \cdot f_{2}\left(W^{h 2} \cdot x_{t}+B^{h 2}\right)$

where $W^{h}, W^{r}, W^{i}, W^{o}$, and $W^{h 2}$ are matrices with dimensions $n \times h, h \times n, h \times m, m \times h 2$, and $h 2 \times n$ representing the weights of the state-space neural network, respectively. $B^{h}$ and $B^{h 2}$ are two vectors with $h$ and $h 2$ elements representing biases which have the effect of increasing or lowering the net input of the activation function, depending on whether they are positive or negative, respectively. $f_{1}$ and $f_{2}$ are two activation functions (linear/nonlinear) for describing the behavior of the system. Restated, the external signal of time $t, u_{t}$, and the internal signal of time $t, x_{t}$, are firstly multiplied by the synaptic weights and the biases are used to apply an affine transformation to the signals of the linear combiner. After the activation function transfers the sum of the signals and biases to output signals, these output signals are again multiplied by the synaptic weights and are summed as a system output of time $t, \hat{y}_{t}$, or as an internal signal in next time step. Fig. 3 is the structure of a SSNN which describes the links between neurons and the above two equations. 

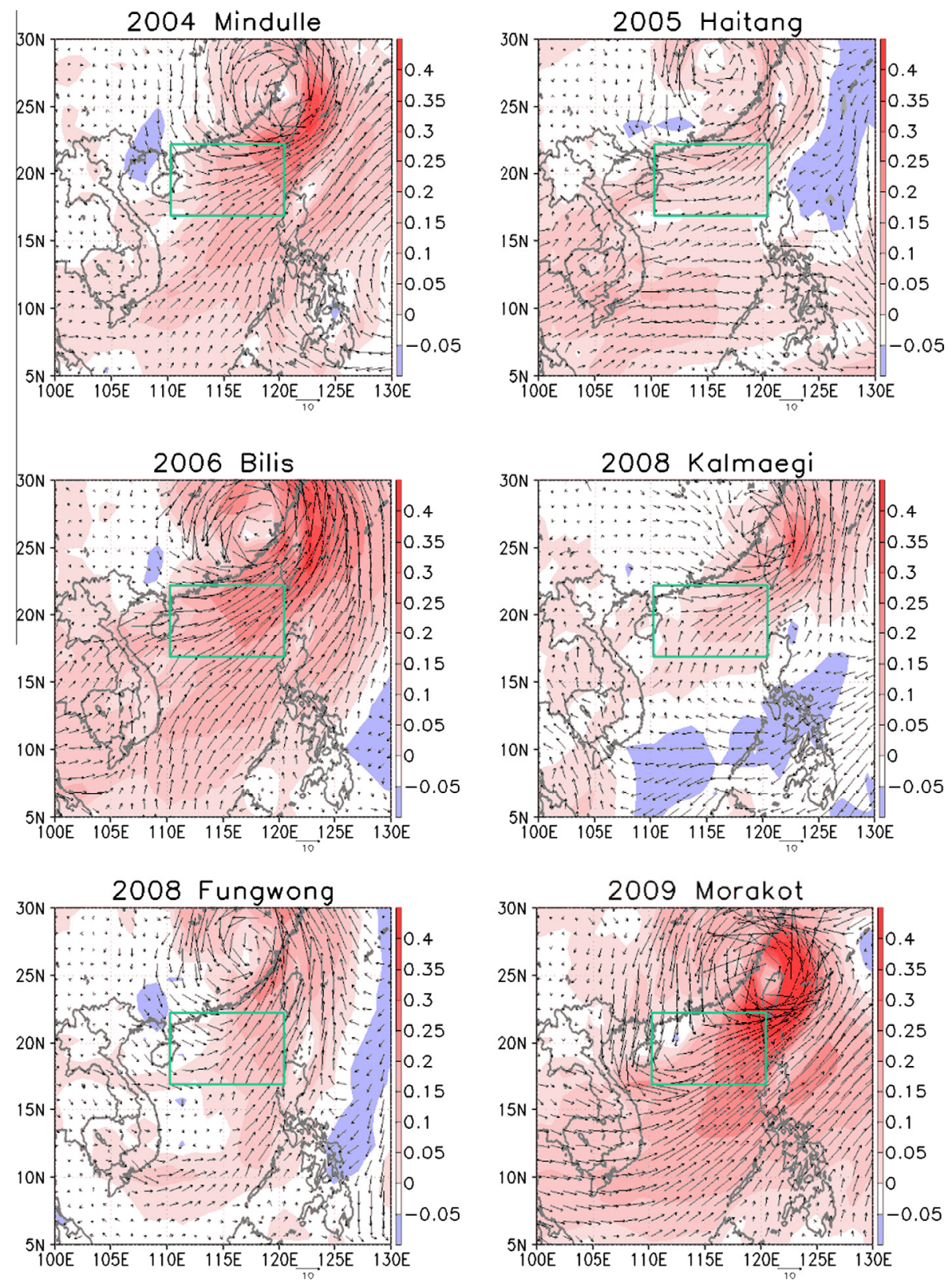

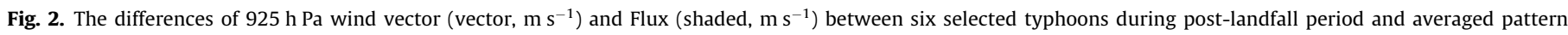

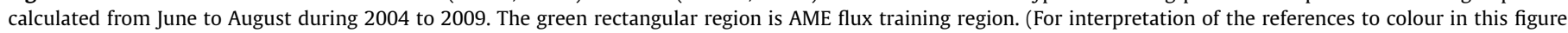
legend, the reader is referred to the web version of this article.)

Table 1

The profiles of selected typhoon events.

\begin{tabular}{|c|c|c|c|c|c|c|c|c|}
\hline \multirow[t]{2}{*}{ Year } & \multirow[t]{2}{*}{ Typhoon } & \multirow[t]{2}{*}{ Categ. } & \multicolumn{3}{|c|}{ Pricipitation in Tsengwen Reservoir Watershed } & \multicolumn{3}{|c|}{ Translation speed } \\
\hline & & & $\operatorname{PrL}(\mathrm{mm})$ & $\mathrm{LF}(\mathrm{mm})$ & $\mathrm{PoL}(\mathrm{mm})$ & $\operatorname{PrL}\left(\mathrm{m} \mathrm{s}^{-1}\right)$ & $\mathrm{LF}\left(\mathrm{m} \mathrm{s}^{-1}\right)$ & $\operatorname{PoL}\left(\mathrm{m} \mathrm{s}^{-1}\right)$ \\
\hline 2004 & Mindulle & 2 & 1 & 109 & 1134 & 4.35 & 2.8 & 5.17 \\
\hline 2005 & Haitang & 3 & 390 & 1319 & 1939 & 2.46 & 4.27 & 2.49 \\
\hline 2006 & Bilis & TS & 116 & 350 & 1045 & 6.06 & 8.83 & 3.78 \\
\hline 2008 & Kalmaegi & 1 & 49 & 2659 & 1369 & 5.46 & 2.62 & 6.9 \\
\hline 2008 & Fungwong & 2 & 2 & 62 & 480 & 5.73 & 5.82 & 5.3 \\
\hline 2009 & Morakot & 1 & 1311 & 2338 & 5736 & 2.06 & 2.48 & 2.08 \\
\hline
\end{tabular}

Note: Categ.: Category; PrL: pre-landfall; LF: landfall; PoL:post-landfall.

\subsection{Flowchart and performance evaluation}

Fig. 4 summarizes the procedures of TRCM with AME in flowchart and the application to the rainfall-runoff simulation. We use the DIFF and the SWFlux to identify the threshold of SWFlux in each station, and further compute the EFlux. The EFlux is used in AME to improve TRCM. With the AME improved TRCM for each rain gauge station, we use the kriging method to objectively 
Table 2

The altitude and effective flux threshold of the selected rain gauge stations.

\begin{tabular}{|c|c|c|c|c|c|c|c|c|c|c|}
\hline \multirow[t]{2}{*}{ Rain gauge } & \multirow[t]{2}{*}{ Altitude (m) } & \multicolumn{9}{|c|}{$\begin{array}{l}\text { Threshold of effective flux }\left(\mathrm{m} \mathrm{s}^{-1}\right) \\
5 \text { Typhoons without }\end{array}$} \\
\hline & & Mindulle & Haitang & Bilis & Kalmaegi & Fungwong & Morakot & 6 typhoons & Mean & S.D. \\
\hline Alishan & 2413 & 0.16 & 0.18 & 0.15 & 0.17 & 0.17 & 0.16 & 0.17 & 0.17 & 0.01 \\
\hline Tatung & 1246 & 0.17 & 0.19 & 0.16 & 0.18 & 0.18 & 0.17 & 0.17 & 0.17 & 0.01 \\
\hline Laiton & 1090 & 0.16 & 0.17 & 0.15 & 0.17 & 0.17 & 0.17 & 0.17 & 0.17 & 0.01 \\
\hline Tsaolin & 1000 & 0.18 & 0.20 & 0.16 & 0.19 & 0.18 & 0.20 & 0.18 & 0.18 & 0.01 \\
\hline Kungtien & 768 & 0.19 & 0.20 & 0.15 & 0.17 & 0.17 & 0.20 & 0.16 & 0.18 & 0.02 \\
\hline Maton & 245 & 0.15 & 0.17 & 0.15 & 0.17 & 0.17 & 0.17 & 0.16 & 0.16 & 0.01 \\
\hline Tsengwen & 207 & 0.18 & 0.19 & 0.16 & 0.19 & 0.18 & 0.19 & 0.18 & 0.18 & 0.01 \\
\hline
\end{tabular}

Note: S.D.: Standard deviation.

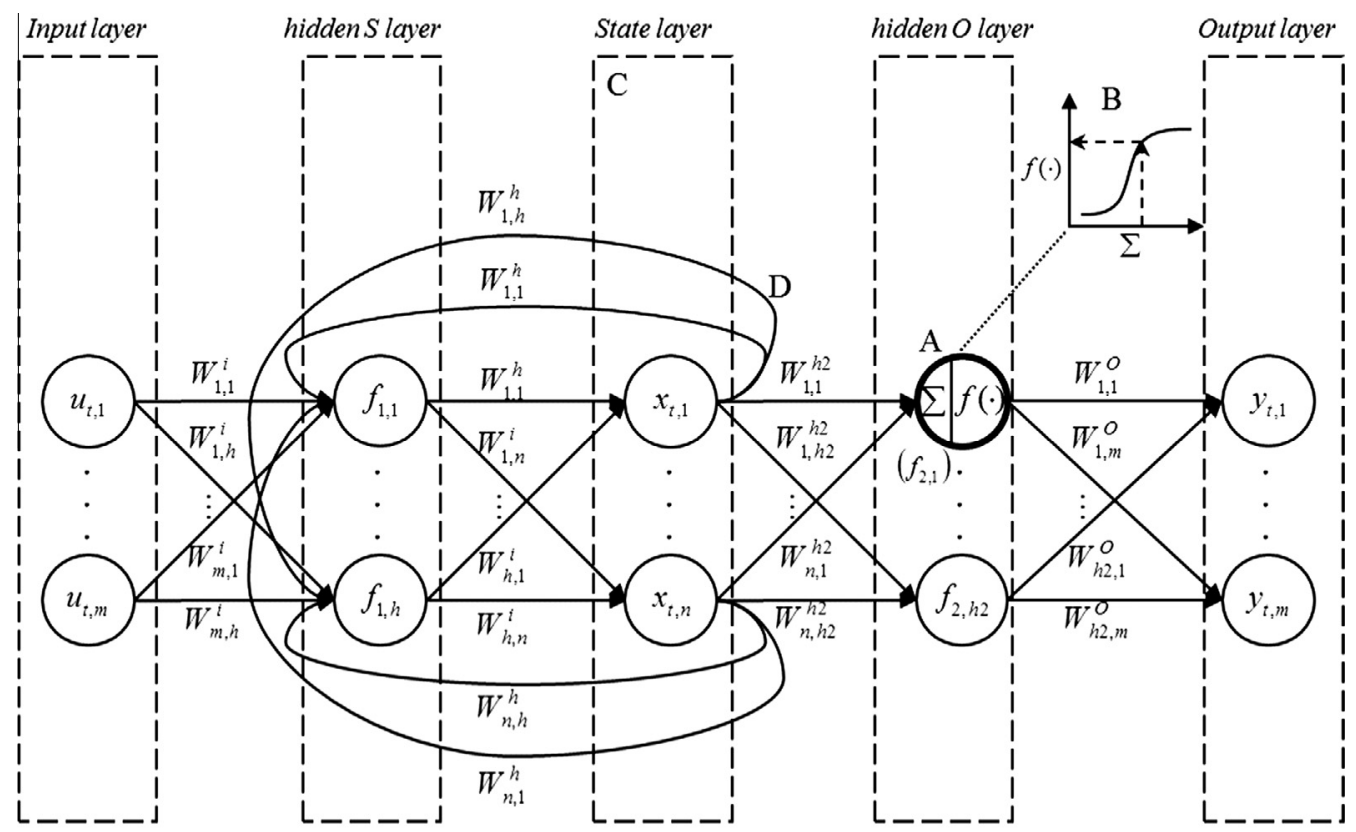

A: neurons; B: activation functions; C: layers; D: connections.

Fig. 3. The structure of a state space neural network.

estimate average rainfall for the Tsengwen Reservoir watershed. In addition, the rule of mass balance is used to calculate both the effective rainfall from the average rainfall and the direct runoff from the inflow of the Tsengwen Reservoir. Firstly, a non-tracerbased method, simple graphical approach (Linsley et al., 1975), is adopted to identify the direct runoff from the observed inflow by removing base flow. Once the total volume of the direct runoff is determined, the effective rainfall could be carried out by the phi index method for rainfall loss (Chow, 1959). The effective rainfall and the direct runoff are used as the input and output of the hydrological rainfall-runoff model developed by Pan and Wang (2004).

According to the flowchart, there are three major components to improve the flood forecasting, including a linear regression between effective southwest monsoon (EFlux) and the difference between observed rainfall and simulated rainfall by TRCM (Diff), a FNN for estimating the residuals between linear regression and Diff, and a SSNN for performing flood forecasting based on TRCM with AME. Therefore, the weights of FNN and SSNN could be regarded as the key model parameters.

Hashem (1992) pointed out that one of the key factors that affect the success of ANN, is the ability to extract information about the model structure and the relationships between its inputs and outputs from the trained network. Such information is essential for model validation and for process optimization and control
(Hashem, 1992). Therefore, all weights adopted in this study are optimized by a conjugate gradient back-propagation with Fletcher-Reeves updates (Scales, 1985) that is the rationale on the particular set of weights. Due to the optimization of weights of ANNs, we did not experimented with other sets of values.

Our performanceof hydrological simulation is evaluated via four criteria as follows:

(a) The coefficient of efficiency, $C E$, is defined as

$C E=1 \frac{\sum_{t=1}^{t}\left[Q_{\text {est }, t}-Q_{o b s, t}\right]^{2}}{\sum_{t=1}^{t}\left[Q_{\text {est } t, t}-\bar{Q}_{o} b s, t\right]^{2}}$

where $Q_{\text {est }, t}$ denotes the discharge of the simulated hydrograph for time index $t\left(\mathrm{~m}^{3} \mathrm{~s}^{-1}\right), Q_{o b s, t}$ is the discharge of the observed hydrograph for time index $t\left(\mathrm{~m}^{3} \mathrm{~s}^{-1}\right)$. The better the fit, the closer $C E$ is to 1.

(b) The error of peak discharge, $E Q_{p}(\%)$, is defined as

$E Q_{p}(\%)=\frac{Q_{p, e s t}-Q_{p, o b s}}{Q_{p, o b s}} \times 100 \%$

where $Q_{p \text {,est }}$ denotes the peak discharge of the simulated hydrograph $\left(\mathrm{m}^{3} \mathrm{~s}^{-1}\right)$ and $Q_{p, o b s}$ is the peak discharge of the observed hydrograph $\left(\mathrm{m}^{3} \mathrm{~s}^{-1}\right)$.

(c) The error of the time for peak to arrive, $E T_{p}$, is defined as 


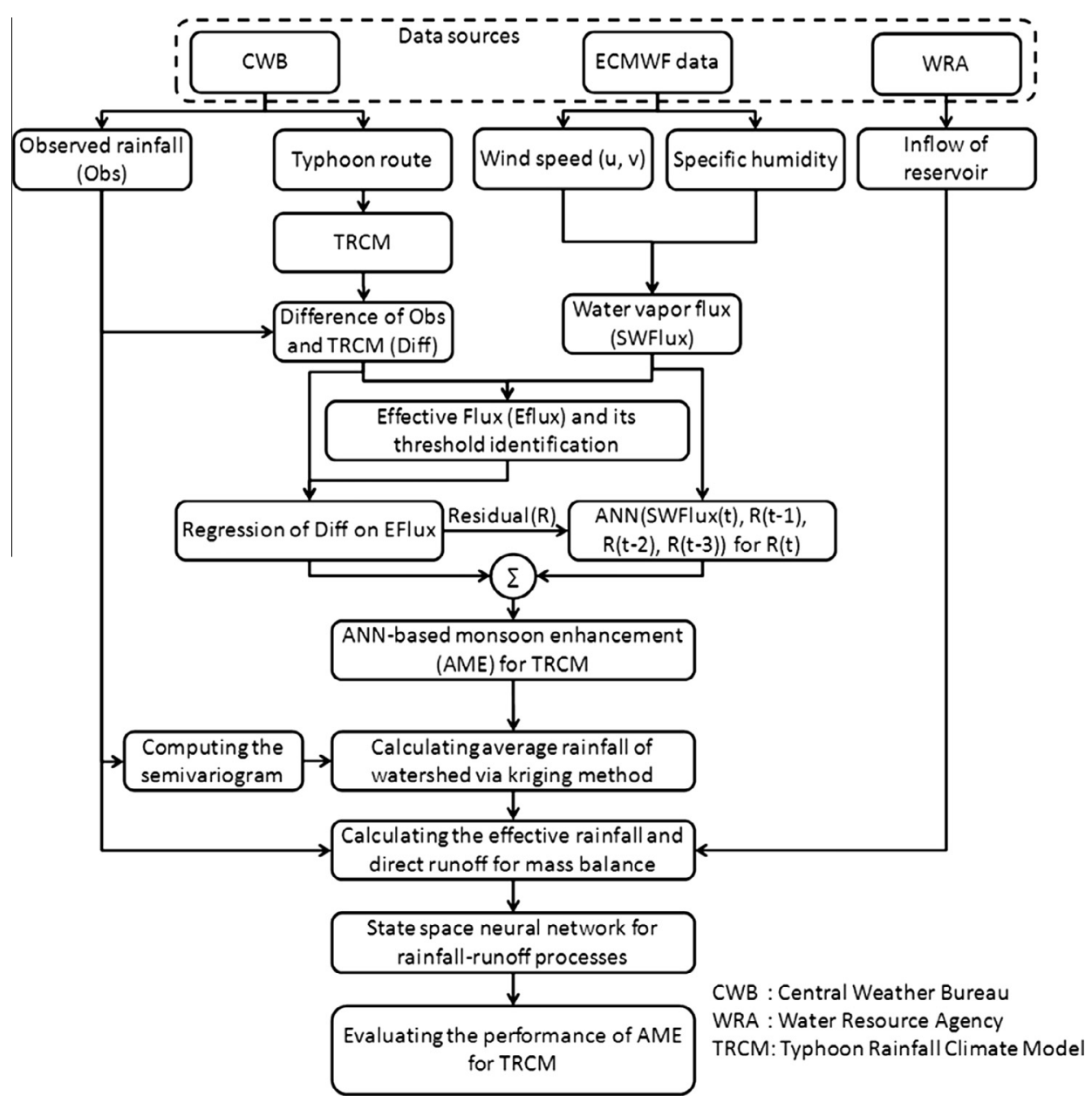

Fig. 4. The flowchart of the TRCM with AME and its application to runoff simulation.

$E T_{p}=T_{p, e s t}-T_{p, o b s}$

where $T_{p, e s t}$ denotes the time for the simulated hydrograph peak to arrive ( $h$ ) and $T_{p, o b s}$ represents the time required for the observed hydrograph peak to arrive (h).

(d) The error of total discharge volume, VER (\%), is defined as

$\operatorname{VER}(\%)=\frac{\left(\sum_{t=1}^{T} Q_{e s t, t}-\sum_{t=1}^{t} Q_{o b s, t}\right)}{\sum_{t=1}^{T} Q_{o b s, t}} \times 100 \%$

where $Q_{\text {est.t }}$ denotes the discharge of the simulated hydrograph for time index $t\left(\mathrm{~m}^{3} \mathrm{~s}^{-1}\right), Q_{\text {obs }, t}$ is the discharge of the observed hydrograph for time index $t\left(\mathrm{~m}^{3} \mathrm{~s}^{-1}\right)$. The better the fit, the closer VER is to 0 .

\section{Results and discussions}

\subsection{Threshold analysis of effective flux}

Fig. 5 is the scatter plots of the DIFF data and SWFlux in seven stations. The flux threshold varies in a similar spatial pattern as shown in Fig. 5. The variance of the flux threshold of each rain gauge station is conceivably induced by the interaction of southwest monsoon, typhoon rainfall, and regional environmental condition, like the translation speed of typhoons. To identify the threshold of the effective moisture flux, each 30 data of SWFlux are averaged with increasing rainfall intensity, and a transition point is carried out based on the maximum slop difference of two linear regressions for two segments. The thresholds of effective moisture flux at 7 stations for all test cases are shown in
Table 2. The lower the threshold, the larger the rainfall enhancement is expected. Table 2 suggests that SWFlux threshold in general the smallest (largest) without Typhoon Bilis (Typhoon Haitang) in the data base. This is due to the fact that Typhoon Bilis is with large SWFlux but its small rainfall amount can be attributed to the typhoon's fast translation speed. On the other hand TyphoonHaitang is with a smaller SWFlux and a larger rainfall due to its slow moving. Briefly, most results of cross analysis ranges between one standard deviation, and the threshold identified from all typhoon cases (the column "6 typhoons" in Table 2) could be the reasonable standard of EFlux for triggering extra typhoon rainfall.

Fig. 6(a) shows transition of the threshold of effective flux among rain gauge stations through cross analysis of six typhoons. The variance of the flux threshold of each rain gauge station is induced by the interaction of southwest monsoon, typhoon rainfall, and regional environmental condition, like the translation speed of typhoons. Briefly, most results of cross analysis ranges between one standard deviation, except Typhoon Bilis, and the threshold identified from all typhoon cases (the column "6 typhoons" in Table 2) could be the reasonable standard of EFlux for triggering extra typhoon rainfall. Fig. 6(b)-(d) shows the relation between the threshold of EFlux for each rain gauge and different geographical and hydrological factors, including elevation, zonal distances from the lowest rain gauge Tsengwen station, and the cumulative rainfall of each rain gauge. To compare all factors above, each factor is normalized between 0 and 1 following the rule:

$\left(F_{\text {station }}-F_{\min }\right) /\left(F_{\max }-F_{\min }\right)$ 

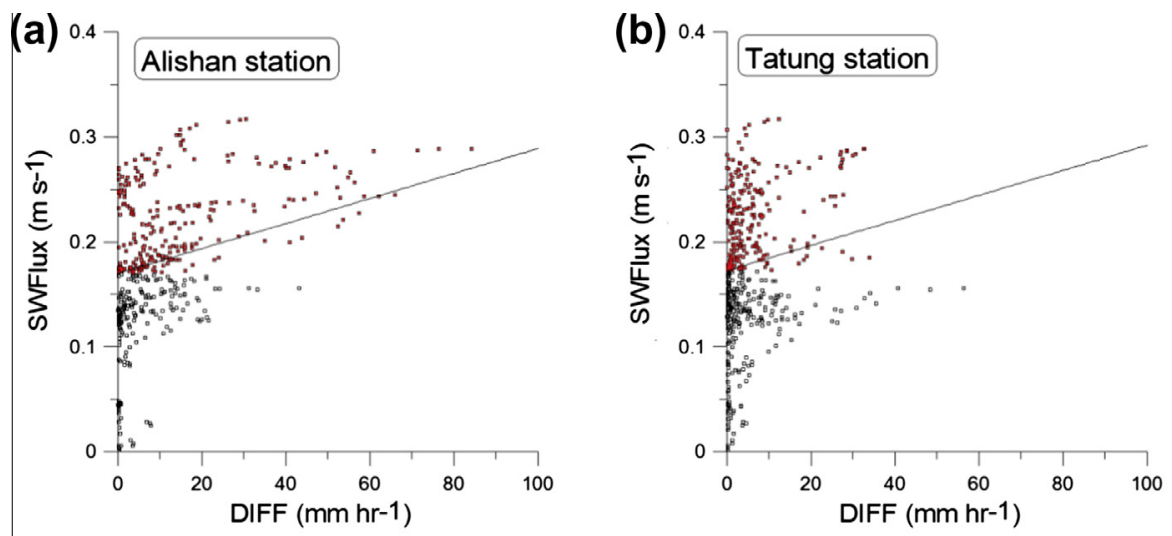

(c)

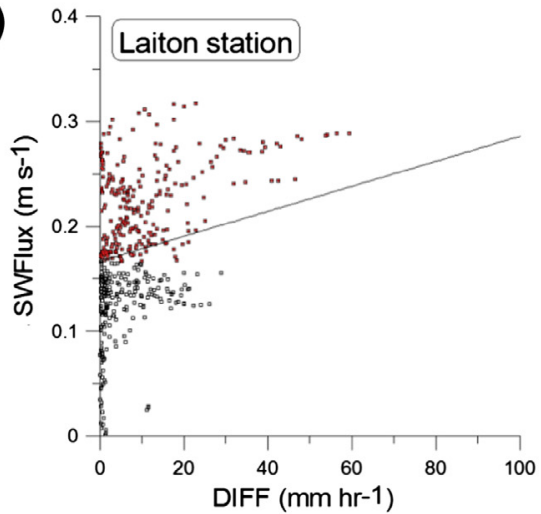

(e)

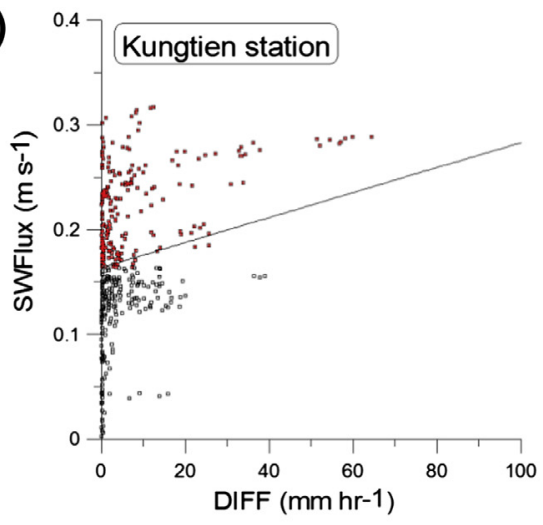

(g)

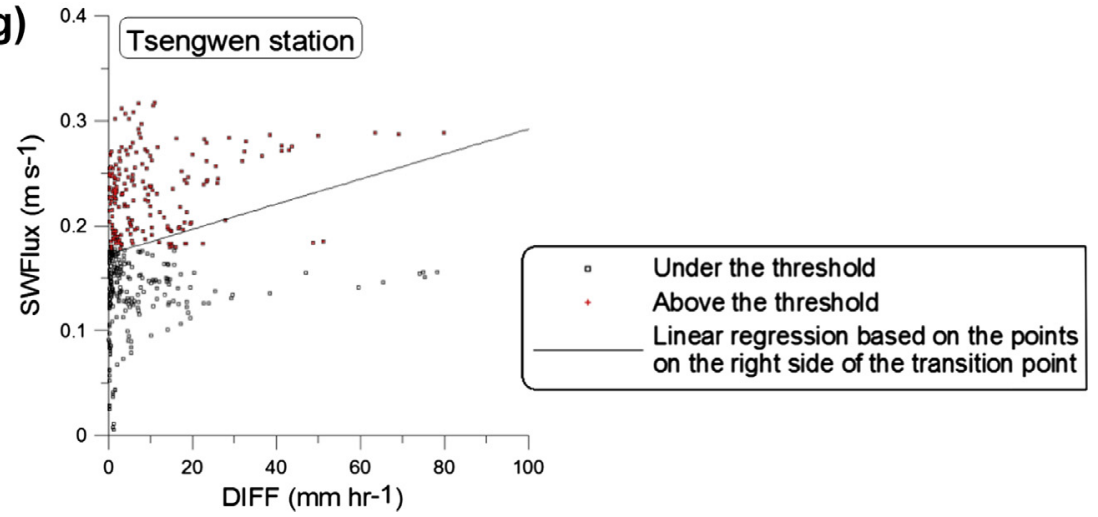

(d)

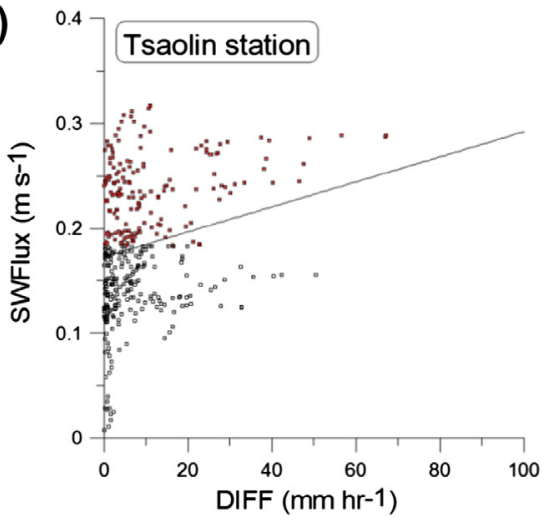

(f)

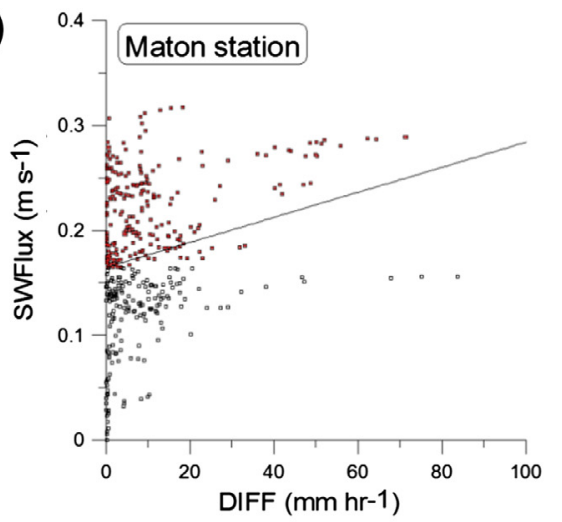

Fig. 5. The scatter plot of the DIFF and SWFlux at (a) Alisan, (b) Tatung, (c) Laiton, (d) Tsaolin, (e) Kungtien, (f) Maton, and (g) Tsengwen.

$F_{\text {station }}$ is the factor of the evaluated rain gauge; $F_{\max }$ and $F_{\min }$ means the maximum and minimum value of the factor in whole rain gauges. Fig. 6(b) indicates there is no direct relation between 

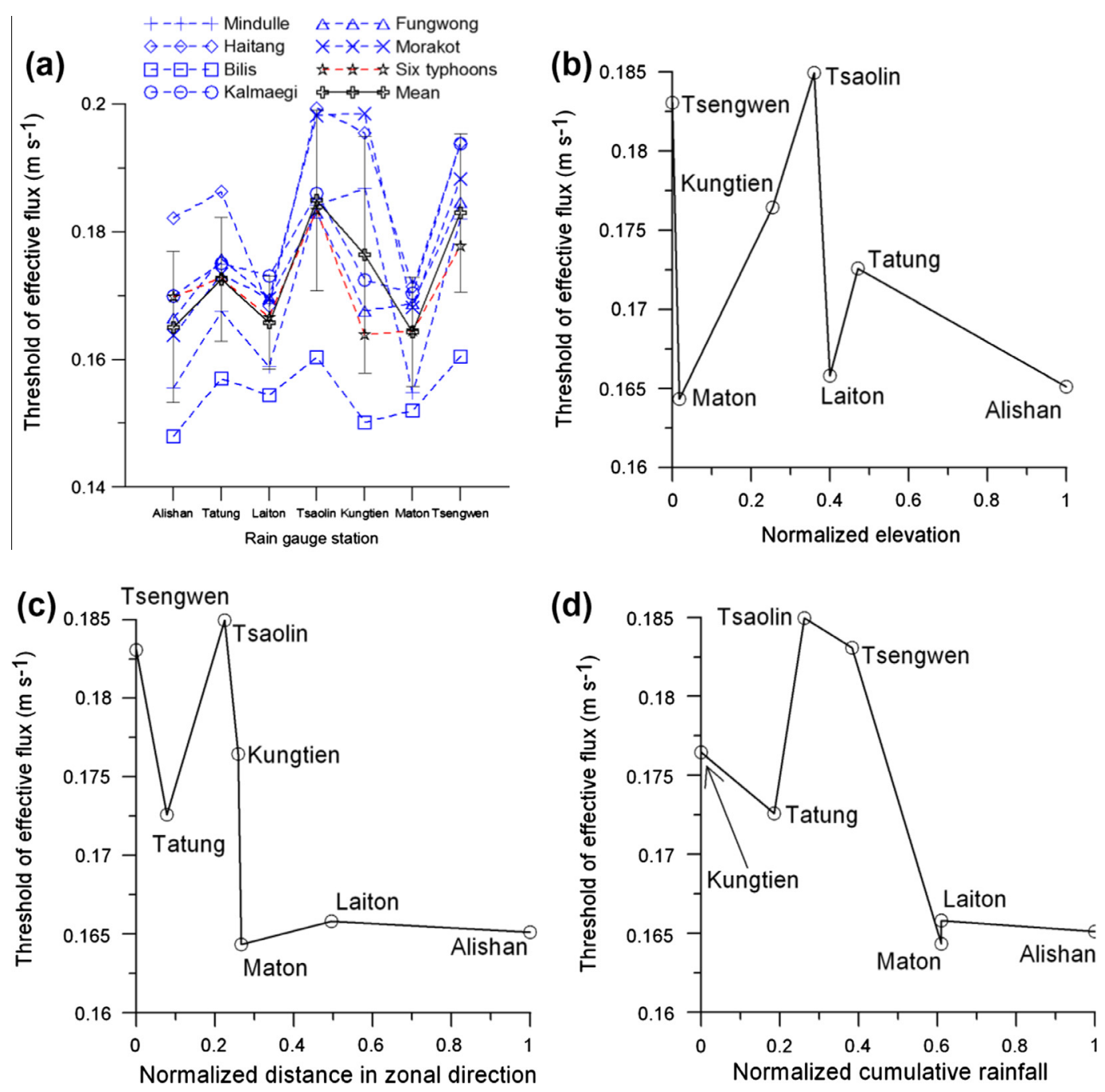

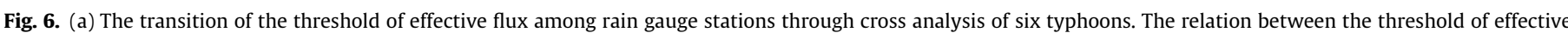
Flux for each rain gauge and normalized (b) elevation, (c) zonal distance, and (d) the cumulative rainfall of each rain gauge station.

the factors, elevation and zonal distance to Tsengwen rain gauge station, is related to the description of Kungtien and Tatung rain gauge stations because these two stations locate on the boundary in the downstream of the Tsengwen reservoir watershed. The two stations were classified into the high elevation group based on elevation factor. However, the factor, zonal distance of each rain gauge station to Tsengwen rain gauge station, is better to describe the topography high in the East and laying down to the West. The high altitude upstream stations of Alishan, Laiton and Maton are with the larger zonal distance (see also Table 2 and Fig. 1). These upstream high altitude stations are with lower threshold. Fig. 6(d) suggests that these upstream high altitude stations are also with the larger rainfall. The results indicate that the flux threshold is related to the topographic lifting of the moist air, with lower threshold in the upstream high altitude stations in the watershed.

\subsection{Average rainfall of the Tsengwen Reservoir watershed}

Fig. 7 presents the scatter plot of the average observed and estimated rainfall intensity $\left(\mathrm{mm} \mathrm{h}^{-1}\right)$ via TRCM with/without AME. Fig. 7 demonstrates the efficacy of the AME because the slope of linear regression line of the TRCM with AME is (slope: 0.68 ) is closer to one than that of the TRCM without AME (slope: 0.38). The hourly rainfall of TRCM is estimated by climatology maps, this model tends to underestimate the larger rainfall and overestimate the light rainfall (or no rain) (Lee et al., 2006; Yeh, 2002). Thus, these six typhoons' rainfall estimations of TRCM in Fig. 7 are underestimated because they are with strong southwesterly flow. Fig. 8 demonstrates the observed rainfall intensity and rainfall intensity prediction of TRCM with $\mathrm{AME}_{\mathrm{wt}}$ (all six cases in the training data base of AME, Model A), and TRCM with $\mathrm{AME}_{\mathrm{cv}}$ (test case removed from the training data base of AME, Model B), and TRCM (Model C), and the SWFlux. In these three models, Model B is really an operational rainfall forecasting work to achieve the purpose of this study because the test event is removed from the training data set. It is not surprising that the Model A with all the test cases in the AME training results in predictions close to the observations. On the other hand, Model B prediction is still better than the original TRCM (Model C) prediction, in that the amount and the multiple peak of rainfall are better predicted. The fact that the Model $B$ in general yields prediction resembles Model A suggests that the AME method is robust. Fig. 8 further suggests that heavy rainfall prediction is usually occurred concurrently with the SWFlux. Moreover, abundant rainfall often happens in the post-landfall period for slow moving storms due to the long duration of typhoon circulation and continuous monsoon water vapor supply which TRCM cannot simulate well. On the other hand, Typhoon Bilis (Typhoon Morakot) is with very fast (slow) translation speed during post-landfall period, the prediction of Model B is overestimated (underestimated) in the presence of significant SWFlux. 


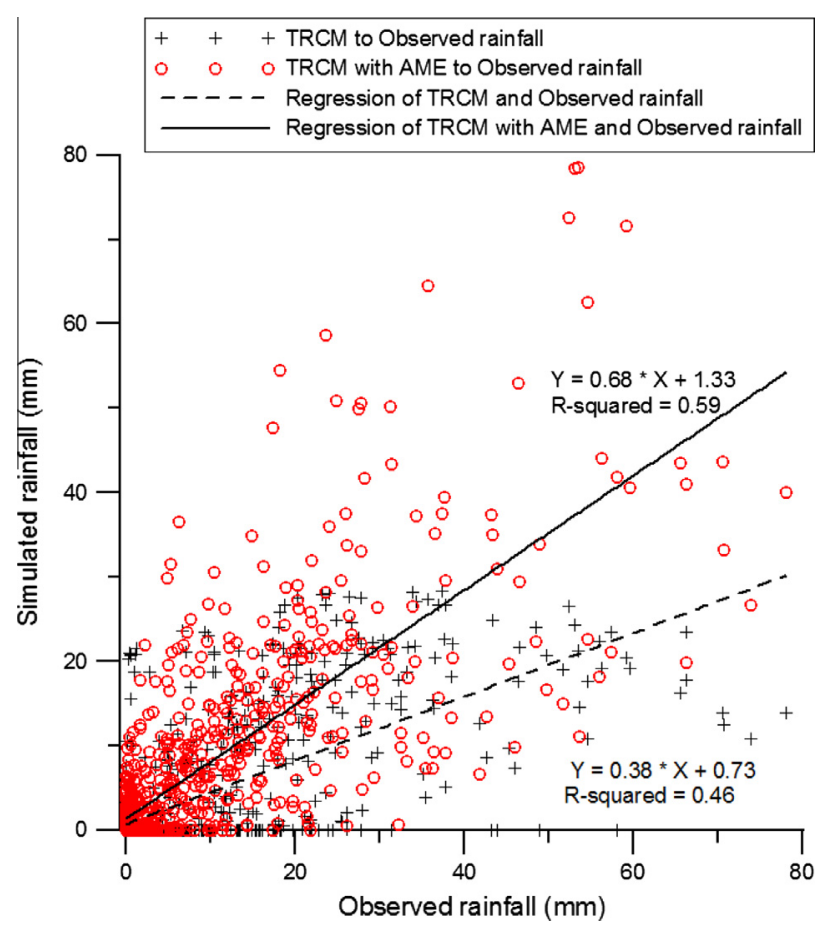

Fig. 7. The performance of the TRCM and the TRCM with AME to observed rainfall intensity $\left(\mathrm{mm} \mathrm{h}^{-1}\right)$ of the Tsengwen Reservoir watershed.

One of the basic assumption in AME is maximum intensity of the SWFlux would induce the maximum watershed rainfall if all other relevant factors are equal and which in reality they may not (Pan et al., 2011). Therefore, the rainfall pattern of Typhoon Morakot is highly related to the pattern of water vapor flux because the slow translation speed provides a strong connection between Typhoon Morakot and southwest monsoon that can meet the assumption mentioned above. However, the fast translation speed of Typhoon Bilis decreases the effect of southwest monsoon on water vapor supply that weakens the assumption mentioned above. The inclusion of translation speed factor in the AME scheme is a subject of future work. More cases of typhoon with strong southwest monsoon are required for the training purpose.

\subsection{The performance of flood forecasting}

Through the indirect system identification algorithm proposed by Pan and Wang (2005), the SSNN of the Tsengwen Reservoir watershed is built as a single-input-single-output model with 5-order state space based on the effective observed rainfall and direct runoff. Table 3 gives the performances of the hydrological model based on different estimated rainfall for 1-h-ahead flood forecasting of six typhoons. Except for case of Typhoon Bilis, all other cases with observations as input have $C E$ ranges from 0.9 to $0.95, E T_{p}$ ranges from 0 to $1 \mathrm{~h}$, and VER ranges from $-9.83 \%$ to $1.21 \%$. These values of $C E, E T_{p}$ and $V E R$ demonstrate the applicability of the SSNN model for flood forecasts. The observation input, however, underestimates the $E Q_{p}$ for Typhoons Mindulle, Haitang and Bilis, probably due to the fact that the unit hydrographs of these three typhoons are sharper than that of the SSNN. Thus the peak flow in these cases is underestimated. Model B cases without Typhoon Fungwong, have the same or better performance in $E T_{p}$ as compared to that with the observation as input. The poor performance of Typhoon Fungwong in $E T_{p}$ may be due to the fact that AME adds much more rainfall to the TRCM prediction after the peak rainfall (see also Fig. 9).

The hyetographs of six typhoon cases and the hydrographs of 1h-ahead direct runoffs are illustrated in Fig. 9. Fig. 9 also presents event series of the rainfall errors ofModel C, and Model B, Model A, observed effective rainfall, and direct runoff. Fig. 9 indicates that the time lag between peak rainfall and peak inflow of Typhoon Bilis is not the same as that of other typhoons and thus is with a different rainfall-runoff relation. Fig. 9 also suggests that the significant underestimation of Model C precipitation (red dots line) lead to the underestimation of runoff processes (red line). Therefore, the Model C runoff in Table 3 shows the poor performances of six typhoons' 1-h-ahead flood forecasting. Furthermore, the hydrographs produced by the estimated rainfalls of Model A and Model B (purple line and green line) are closer to that of observed runoff (black line) in Fig. 9 due to the AME improvement of TRCM.

Table 4 gives the average performances of the hydrological models based on different rainfall estimations for flood forecasts $1-3 \mathrm{~h}$ ahead. Table 4 suggests the Model B improvement over the model $\mathrm{C}$ not only by $51 \%$ in peak discharge, and $64 \%$ in total discharge volume, but also from 0.38 to 0.66 ( $1 \mathrm{~h}$ ahead) in coefficient efficiency. The Model A with test case in the training in

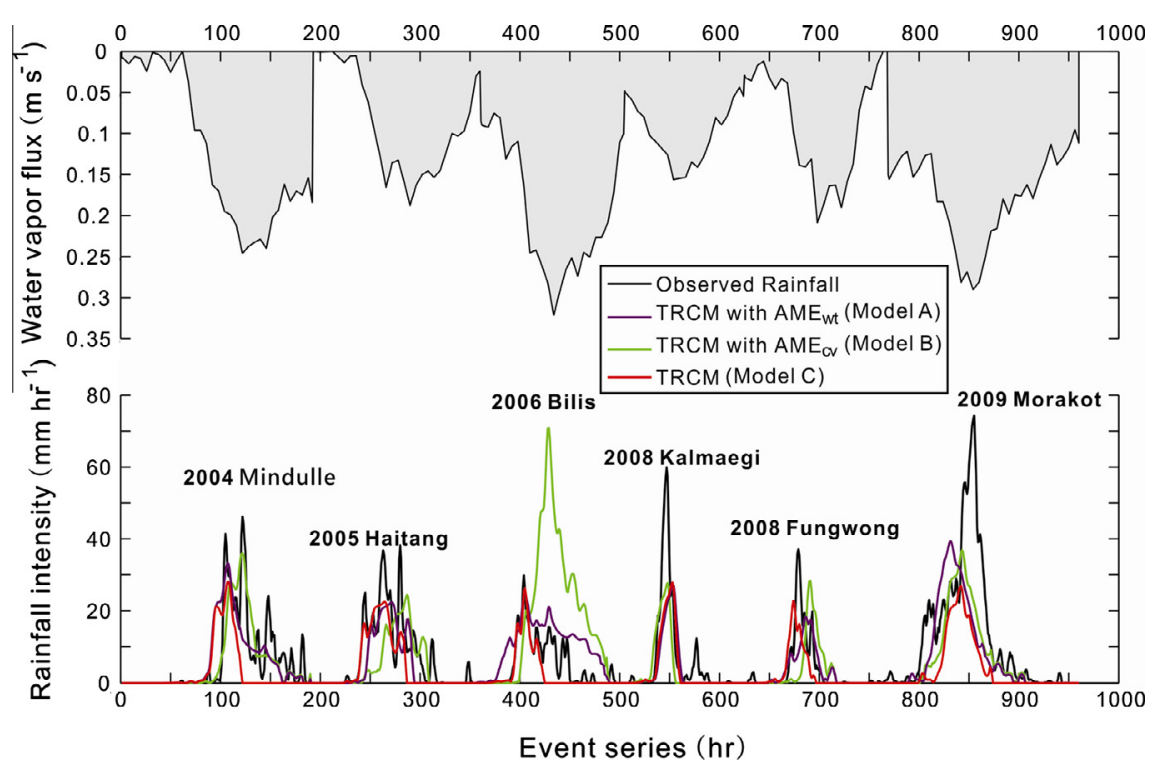

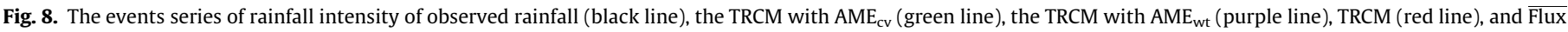
(gray). (For interpretation of the references to color in this figure legend, the reader is referred to the web version of this article.) 
Table 3

The performance of the hydrological model based on different estimated rainfall for 1-h-ahead flood forecasting of six typhoons.

\begin{tabular}{|c|c|c|c|c|c|c|c|c|}
\hline & Observation & Model A & Model B & Model C & Observation & Model A & Model B & Model C \\
\hline & $C E$ & & & & $E Q_{p}(\%)$ & & & \\
\hline Mindulle & 0.90 & 0.62 & 0.81 & 0.00 & -23.92 & -61.94 & -29.94 & -68.27 \\
\hline Haitang & 0.90 & 0.64 & 0.51 & 0.60 & -36.55 & -47.98 & -37.98 & -53.44 \\
\hline Bilis & 0.83 & 0.67 & 0.72 & -0.11 & -21.77 & -31.63 & 2.83 & -20.43 \\
\hline Kalmaegi & 0.94 & 0.58 & 0.77 & 0.67 & 1.50 & -33.72 & -35.32 & -31.94 \\
\hline Fungwong & 0.93 & 0.75 & 0.27 & 0.46 & 1.81 & -18.67 & -0.86 & -41.78 \\
\hline \multirow[t]{2}{*}{ Morakot } & 0.95 & 0.78 & 0.87 & 0.67 & 5.09 & -45.54 & -31.95 & -53.81 \\
\hline & $E T_{p}(\mathrm{~h})$ & & & & VER (\%) & & & \\
\hline Mindulle & 1 & -9 & 1 & -9 & 0.46 & -16.64 & -12.14 & -61.95 \\
\hline Haitang & 1 & -9 & 5 & -14 & -5.33 & -28.14 & -24.04 & -35.95 \\
\hline Bilis & -25 & -24 & 1 & -24 & -12.73 & 27.95 & 8.05 & -50.87 \\
\hline Kalmaegi & 1 & 6 & 3 & 6 & -1.04 & -24.40 & -32.12 & -24.16 \\
\hline Fungwong & 0 & 11 & 11 & -6 & -9.83 & -12.79 & -23.91 & -40.00 \\
\hline Morakot & 1 & 3 & 3 & 3 & 1.21 & -17.99 & -9.85 & -46.57 \\
\hline
\end{tabular}

Model A: TRCM with $\mathrm{AME}_{\mathrm{wt}}$; Model B: TRCM with $\mathrm{AME}_{\mathrm{CV}}$; Model C: TRCM only.
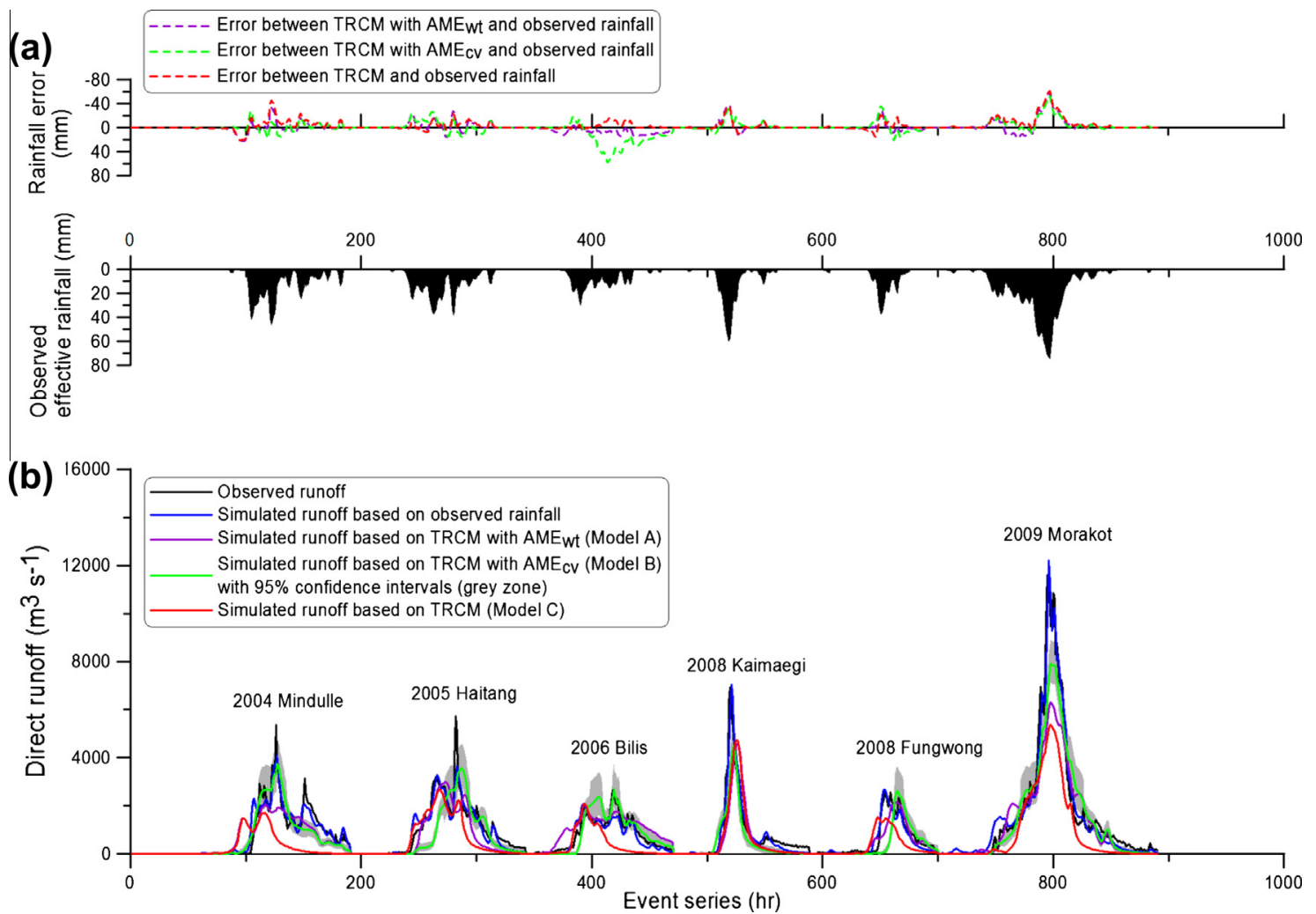

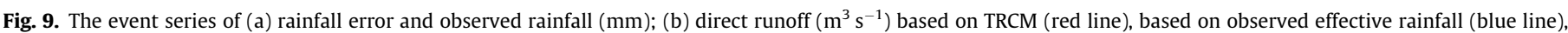

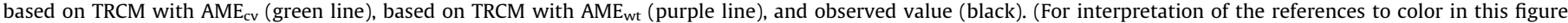
legend, the reader is referred to the web version of this article.)

Table 4

The average performances of hydrological models based on different estimated rainfalls for 1 to 3 -h-ahead flood forecasting.

\begin{tabular}{lccrlll}
\hline Leading time $(\mathrm{h})$ & 1 & 2 & 3 & 1 & 2 & 3 \\
\hline & $C E$ & & & $E Q_{P}(\%)$ & & \\
Observation & 0.91 & 0.89 & 0.86 & -12.31 & -12.90 & -26.49 \\
Model A & 0.67 & 0.64 & 0.58 & -39.91 & -39.93 & -49.33 \\
Model B & 0.66 & 0.61 & 0.53 & -22.20 & -22.18 & -32.49 \\
Model C & 0.38 & 0.35 & 0.30 & -44.94 & -44.32 & -53.04 \\
& & & & $V E R(\%)$ & & \\
Observation & -3.50 & -3.33 & -5.67 & -4.54 & -4.71 & -16.87 \\
Model A & -3.67 & -2.83 & -2.00 & -12.00 & -12.29 & -23.48 \\
Model B & 4.00 & 4.67 & 5.67 & -15.67 & -15.37 & -23.16 \\
Model C & -7.33 & -7.17 & -6.50 & -43.25 & -43.63 & -51.33
\end{tabular}

Model A: TRCM with $\mathrm{AME}_{\mathrm{wt}}$; Model B: TRCM with AME $\mathrm{CV}$; Model C: TRCM only. general is slightly better than Model B without the test case except for the peak discharge. This may be due to the fact that Model A are usually with larger rainfall than the Model B, and thus the mass balance rule may reduce too much of the rainfall peak for Model A. Furthermore, Model C is able to predict the peak of flood in advance because the peaks of the estimated rainfalls of the TRCM without an AME are always earlier than or equal to the observed rainfalls. The arrival time of peak flow for Model $\mathrm{B}$ is on the average around $5 \mathrm{~h}$ late. The major error source could be induced by adding much more rainfall to TRCM after the observed peak rainfall to cause the significant delay of the rainfall peaks of Typhoon Bilis and Fungwong predicted by Model B as shown in Fig. 8. 


\section{Conclusions}

The typhoon rainfall climate model (TRCM), based on 371 stations over Taiwan during 1989-2008, gives reasonable precipitation estimates on each rain gauge station for 24-36 h time scale for typhoon. However, this model underestimated the rainfall amount of some typhoons with significant southwest monsoon because of TRCM based on the typhoon rainfall climatology. This phenomena influence on the upstream of Tsengwen Reservoir watershed. This study uses an ANN-based southwest monsoon rainfall enhancement (AME) to improve the typhoon rainfall and runoff forecast over the Tsengwen Reservoir watershed in Taiwan. The strength of the southwest monsoon is evaluated in the moist flux in the detecting zone located at sea over southwestern Taiwan. The AME is composed of linear regression and artificial neural network (ANN) to estimate the effect of summer monsoon on typhoon rainfall. The precipitations of seven rain gauge stations and the southwest monsoon water vapor flux are analyzed to get the spatial distribution of the effective water vapor flux threshold, and the threshold is used to build the AME model. We found that the flux threshold is related to the topographic lifting of the moist air, with lower threshold in the upstream stations in the mountainous watershed. The lower flux threshold is with a larger rainfall amount in the Tsengwen Reservoir watershed. Our main results suggest that TRCM with AME is robust in producing better multiple rainfall peaks for the watershed. The improved rainfall leads to better flood predictions. The improved runoff processes in the watershed, in particular, are most significant in the coefficient of efficiency, peak flow discharge with 51\% improvement, and total volume with $64 \%$ improvement. The drawback of the method perhaps is the arrival time of peak flow for TRCM with AME is on the average around $5 \mathrm{~h}$ late. In a reservoir operation with very short time of concentration, prediction better early than late, the delay of the $5 \mathrm{~h}$ for the arrival time of peak flow require some adjustment for the operation.

Briefly, our method has improved the rainfall forecast of TRCM, and is applied to flood forecasting. It will be useful for weather forecaster and reservoir operator if more typhoon cases with strong southwesterly flow are included for training. However, the only one meteorological factor in our method is southwesterly water vapor flux. Our result also indicates the translation speed of typhoon may influence on the rainfall. The inclusion of translation speed factor in the AME scheme is a subject of future work. More cases of typhoon with strong southwest monsoon are required for the training purpose.

\section{Acknowledgments}

This research was supported by Taiwan's National Science Council through Grants NSC102-2625-M-002-020, NSC100-2111M-002-004-MY3, and NTU-CESRP-102R7604-1 to National Taiwan University. We thank not only Mr. Yi-Chin Chen for his GIS supports, but also the Taiwan Typhoon and Flood Research Institute, the Center for Weather Climate and Disaster Research at National Taiwan University and Taida Institute for Mathematical Sciences for the additional support.

\section{References}

Anctil, F., Asce, M., Rat, A., 2005. Evaluation of neural network streamflow forecasting on 47 watersheds. J. Hydrol. Eng. 10 (1), 85-88.

Bellerby, T., Todd, M., Kniveton, D., Kidd, C., 2000. Rainfall estimation from a combination of TRMM precipitation radar and GOES multispectral satellite imagery through the use of an artificial neural network. J. Appl. Meteorol. 39, 2115-2128. http://dx.doi.org/10.1175/1520-0450(2001) 040<2115:REFACO> 2.0.CO;2.

Brunder, D.G., Coughlin, R.T., McGroarty, E.J., 1981. A program for transition point analysis of experimental data. Comput. Biol. Med. 11, 9-15.
Chang, F.J., Chen, Y.C., 2003. Estuary water-stage forecasting by using radial basis function neural network. J. Hydrol. 270, 158-166.

Chen, S.T., Wu, C.C., Chen, W.J., Hu, J.C., 2008. Rain-area identification using TRMM/ TMI data by data mining approach. J. Adv. Comput. Intell. Inf. 12, 243-248.

Chiang, Y.M., Chang, L.C., Chang, F.J., 2004. Comparison of static-feedforward and dynamic-feedback neural networks for rainfall-runoff modeling. J. Hydrol. 290, 297-311.

Chien, F.C., Kuo, H.C., 2011. On the extreme rainfall of Typhoon Morakot (2009). J. Geophys. Res. 116, D05104. http://dx.doi.org/10.1029/2010JD015092.

Chien, F.C., Liu, Y.C., Lee, C.S., 2008. Heavy rainfall and southwesterly flow after the leaving of Typhoon Mindulle (2004) from Taiwan. J. Meteorol. Soc. Jpn. 86, 1741. http://dx.doi.org/10.2151/jmsj.86.17.

Chow, V.T., 1959. Open-Channel Hydraulics. McGraw-Hill.

Cigizoglu, H.K., 2005. Generalized regression neural network in monthly flow forecasting. Civ. Eng. Environ. Syst. 22 (2), 71-84.

Deka, P., Chandramouli, V., 2005. Fuzzy neural network model for hydrologic flow routing. J. Hydrol. Eng. 10 (4), 302-314.

El-Shafie, A.H., El-Manadely, M.S., 2011. An integrated neural network stochastic dynamic programming model for optimizing the operation policy of Aswan High Dam. Hydrol. Res. 42 (1), 50-67.

French, M.N., Krajewski, W.F., Cuykendall, R.R., 1992. Rainfall forecasting in 294 space and time using a neural network. J. Hydrol. 137, 1-31.

Gardner, M.W., Dorling, S.R., 1998. Artificial neural networks (the multilayer 296 perceptron) - a review of applications in the atmospheric sciences. Atmos. Environ. 32 (14/15), 2627-2636.

Ge, X., Li, T., Zhang, S., Peng, M., 2010. What causes the extremely heavy rainfall in Taiwan during Typhoon Morakot (2009)? Atmos. Sci. Lett. 11, 45-50. http:// dx.doi.org/10.1002/asl.255.

Hashem, S., 1992: Sensitivity analysis for feedforward artificial nerual networks with differentiable activation functions. In: Proceedings of IJCNN, June 1992, Baltimore, Maryland.

Hong, Y., Hsu, K.L., Sorooshian, S., Gao, X., 2004. Precipitation estimation from remotely sensed imagery using an artificial neural network cloud classification system. J. Appl. Meteorol. 43, 1834-1853. http://dx.doi.org/10.1175/JAM2173.1.

Hong, C.C., Lee, M.Y., Hsu, H.H., Kuo, J.L., 2010. Role of submonthly disturbance and 40-50 day ISO on the extreme rainfall event associated with Typhoon Morakot (2009) in Southern Taiwan. Geophys. Res. Lett. 37, L08805. http://dx.doi.org/ 10.1029/2010GL042761.

Hsu, K.L., Gao, X., Sorooshian, S., Gupta, H.V., 1997. Precipitation estimation from remotely sensed information using artificial neural networks. J. Appl. Meteorol. 36, 1176-1190, doi: 10.1175/1520-0450(1997)036<1176:PEFRSI>2.0.CO;2.

Hu, T.S., Lam, K.C., Ng, T., 2005. A modified neural network for improving river flow prediction. Hydrol. Sci. J. 50 (2), 299-318.

Imrie, C.E., Durucan, S., Korre, A., 2000. River flow prediction using artificial neural networks: generalisation beyond the calibration range. J. Hydrol. 233, 138-153.

Lange, N.T., 1999. New mathematical approaches in hydrological modeling - an application of artificial neural networks. Phys. Chem. Earth (B) 24 (1-2), 31-35.

Lee, C.S., Huang, L.R., Shen, H.S., Wang, S.T., 2006. A climatology model for forecasting typhoon rainfall in Taiwan. Nat. Hazards 37, 87-105. http:// dx.doi.org/10.1007/s11069-005-4658-8.

Lee, C.S., Liu, Y.C., Chien, F.C., 2008. The secondary low and heavy rainfall associated with Typhoon Mindulle (2004). Mon. Weather Rev. 136, 1260-1283. http:// dx.doi.org/10.1175/2007MWR2069.1.

Lin, G.F., Chen, L.H., 2005. Application of an artificial neural network to typhoon rainfall forecasting. Hydrol. Process. 19, 1825-1837. http://dx.doi.org/10.1002/ hyp. 5638 .

Lin, G.F., Chen, G.R., Wu, M.C., Chou, Y.C., 2009. Effective forecasting of hourly typhoon rainfall using support vector machines. Water Resour. Res. 45, W08440. http://dx.doi.org/10.1029/2009WR007911.

Linsley, R.K., Kohler, M.A., Paulhus, J.L.H., 1975. Hydrology for Engineers. McGrawHill.

Olsson, J., Uvo, C.B., Jinno, K., Kawamura, A., Nishiyama, K., Koreeda, N., Nakashima, T., Morita, O., 2004. Neural networks for rainfall forecasting by atmospheric downscaling. J. Hydrol. Eng. 9 (1), 1-12. http://dx.doi.org/10.1061/(ASCE)10840688(2004) 9:1(1.

Pan, T.Y., Wang, R.Y., 2004. State space neural networks for short term rainfallrunoff forecasting. J. Hydrol. 297, 34-50. http://dx.doi.org/10.1016/ j.jhydrol.2004.04.010.

Pan, T.Y., Wang, R.Y., 2005. Using recurrent neural networks to reconstruct rainfallrunoff processes. Hydrol. Process. 19, 3603-3619. http://dx.doi.org/10.1002/ hyp.5838.

Pan, T.Y., Wang, R.Y., Lai, J.S., 2007. A deterministic linearized recurrent neural network for recognizing the transition of rainfall-runoff processes. Adv. Water Resour. 30, 1797-1814.

Pan, T.Y., Yang, Y.T., Kuo, H.C. Tan, Y.C. Lai, J.-S., Chang T.J. Lee, C.S., Hsu, H.K., 2011. Improvement of statistical typhoon rainfall forecasting with ANN-based southwest monsoon enhancement. TAO 22, 633-645.

Scales, L.E., 1985. Introduction to Non-Linear Optimization. Springer, New York, NY.

Wang, W.C., Chau, K.W., Cheng, C.T., Qiu, L., 2009. A comparison of performance of several artificial intelligence methods for forecasting monthly discharge time series. J. Hydrol. 374 (3-4), 294-306.

Whitley, R., Hromadka, T.V., 1999. Approximate confidence intervals for design floods for a single site using a neural network. Water. Resour. Res. 35 (1), 203-209.

Yeh, T.C., 2002. Typhoon rainfall over Taiwan area: The empirical orthogonal function modes and their applications on the rainfall forecasting. TAO 13, 449468 